\title{
Integrated Study Programs through e-Learning
}

\author{
Sandra Aguirre, Juan Quemada, Joaquín Salvachúa \\ Universidad Politécnica de Madrid, saguirre $a$ dit.upm.es. jquemada@dit.upm.es, jsr@dit.upm.es
}

\begin{abstract}
In the unstoppable process of globalization and educational convergence, the use of e-Learning as a support tool in educational programs is becoming a growing trend. A wide diversity of proprietary and opensource e-Learning platforms are available. However, these platforms are generally developed independently by different organizations, and different technologies are used in them. As a result, the implementation of integrated study programs by means of e-Learning systems requires the solution of several technical difficulties generated by the heterogeneity of systems. In order to identify the variables, nules and components that should be taken into account in our proposal, we have analyzed several collaboration agreements between universities at national, European and international levels as well as e-Learning frameworks. This paper introduces the design of a federated service-oriented architecture, whose implementation will be based on Web Services. We have developed a prototype that allows the implementation of this architecture. To achieve this goal, we have used an open source platform, such as Moodle and a proprietary platform like Blackboard.
\end{abstract}

Index Terms - Collaboration. Degree programs, e-Learning. SOA.

\section{INTRODUCTION}

In an increasingly global and competitive higher education market. collaboration between universities will be an important strategy gaining access to the global market.

Integrated study programs are playing an increasingly significant role in constructing the European Higher Education Area and the globalization process by promoting close collaboration between academic institutions.

Technologies and communication infrastructures currently offering the conditions for collaboration and development of courses through internet can be a reality.

The use of e-Leaming as a support tool in educational programs is becoming a growing trend. A wide diversity of proprietary and open source e-Learning systems have been developed. However, most of them were design to work in a standalone rather than in a collaborative way. As a result, the implementation of joint degrees by means of e-Learning systems requires the solution of several technical difficulties generated by the heterogeneity of systems.

Service-oriented approaches in e-Learning systems are rapidly gaining popularity with the wide adoption of Web Services, and because of the lower costs of integration coupled with the flexibility and simplification of the configuration. Wilson et al. [1] describe in detail the benefits of this approach.

The purpose of this paper is to present how the use of a service-oriented approach can support the development of integrated degrees in e-Learning systems between universities through e-Learning systems. Our main objective is to allow e-Leaming Systems to be able to work in a collaborative way by combining their data and functionality through the integration of their services. We use policies to manage services in accordance with the agreements established by the universities involved.

We have developed a prototype that allows the implementation of the architecture proposed and analyzed several collaboration agreements to identify variables and rules to be taken into account within our prototype. To achieve this goal, we used an open source platform, such as Moodle [2] and a proprietary platform like Blackboard [3].

The remainder of the paper is organized as follows. Section 2 provides a brief background on integrated degree programs and e-Learning frameworks. Section 3 describes the scenario for which we intend to produce a solution. Section 4 highlights issues related to the methodology used Section 5 presents the proposed architecture. Finally. we present our conclusions and future work.

\section{BACKGROUND}

For the purpose of this paper, we will refer to joint and double degree programs as integrated study programs which are offered in collaboration among academic institutions to award a bachelor, master $\mathrm{O} \mathrm{PD}$ degree.

A joint degree program can be defined [4] as an academic program where students study at (at least) two higher education institutions and receive upon completion of the study program a single degree certificate issued and signed by all the participating institutions jointly.

On the other hand, in a dual or double degree program, students study at (at least) two higher education institutions and receive upon completion of the study program a separate degree certificate from each of the participating institutions.

Joint degrees are seen as a principal instrument for developing the European Higher Education Area (EHEA) and for improving the competitiveness of European higher education around the world [5]

According to the report on Joint and Double Degree Programs in the Transatlantic Context [4], the dual or double degrees appear to be much more common than joint degrees and a large majority of both U.S. institutions and the EU 
institutions plan to develop more joint and double degrees in the future.

In 2003, European ministers agreed [6] "to engage at the national level to remove legal obstacles to the establishment and recognition of such degrees and to actively support the development and adequate quality assurance of integrated curricula leading to joint degrees". Despite of this recommendation, currently exist legal obstacles for recognition of joint degrees.

A great effort is currently being made by the research community to develop initiatives that will allow the interoperability of a learning repository. Among these initiatives we may find: standards and specifications for the content repository such as the IEEE Learning Object Metadata (LOM) Standard. Sharable Content Object Reference Model (SCORM) and IMS Learning Resource Metadata: search interfaces such as Simple Query Interface (SQI) [7] semantic network of interoperable educational systems [8] and educational federated repository systems such as CORDRA [9].

Interesting initiatives have proposed frameworks based on a service-oriented approach for E-Learnig systems, such as: an E-Learning Framework (ELF) [10] that provides a collection of services clustered into logical groups to aid readability and Open Knowledge Initiative (OKI) [11] developed a series of interfaces for service definitions, called Open Service Interface Definition (OSIDs). They give a reference implementation for each of them.

\section{SCENARIO}

Figure 1 below illustrates the scenario of integrated study programs through e-Leaming systems. Two or more universities may participate in the development of joint curriculum by means of their e-Learning Systems.

Students interested in joint degrees can use any of the participating leaming systems when registering and selecting their courses. It will not be necessary to register users in each system. This scenario will allow students to benefit from global curricula and learning environments. thus providing the opportunity to develop language and other skills to work and participate in multicultural environments.

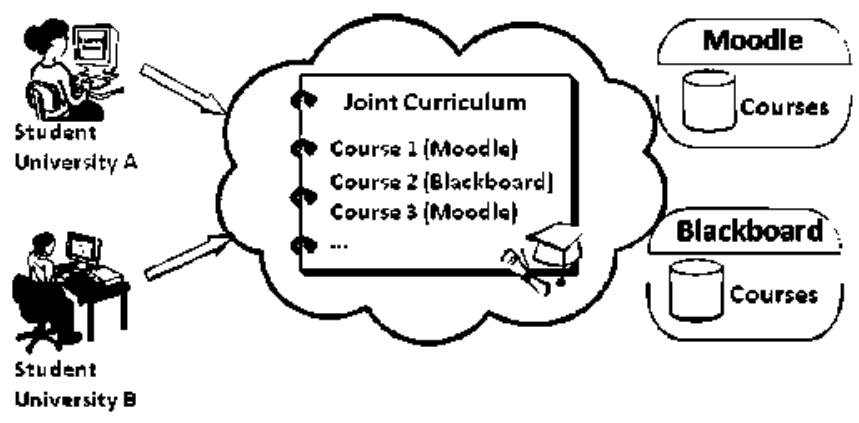

FIGLIRE 1

SCENARIO GF INTEGRATED PROGRAMS THRCUGH E-LEARNING.
Universities should establish collaboration agreements to define responsibilities, rights, rules, joint curriculum and obligations of the parties. Once the agreement has been signed, it have to be translated into a technical language that will allow the carrying out of the academic, administrative, and security services in order to take the integrated study program. The curriculum must be designed by the administrators of each e-Leaming system, who will select and publish the courses that will be part of the joint curriculum. Although these courses will be located and given in different systems, they will constitute the same study plan.

\section{METHODOLOGY}

In order to identify the variables, roles and components that should be taken into account in our proposal, we have analyzed several collaboration agreements between universities at national, European and international levels. In the same way, we have analyzed several e-Learning frameworks to identify the main components that an eLearning system should adapt in order to participate in the development of integrated study programs.

According to Knigh [5] and a study of Joint Degrees [12] several issues have to be addressed to promote the development of joint degrees.

Taking these issues into account, our study of collaboration agreements and e-Learning frameworks allowed us to identify the following problems and challenges to overcome in this scenario:

\section{Technical level}

- Current frameworks were design to work in a standalone rather than in a collaborative way.

- Heterogeneity of e-Learning systems limits the interoperability of contents and services. Different formats for: credit systems, academic calendars and learning objects.

- Administrative support for registration and enrolment for this scenario.

- Design of joint curricula

- Guarantee privacy and security

- Shared authentication (Allow the unique registering of students)

- Internationalization of content

\section{Pedagogical level}

- Motivation. performance and involvement of students in a new environment of collaboration

- Different teaching approaches

\section{Administrative level}

- Tuition feeds and funding

- Sustainability issues

- Institutional engagement 
- Quality assurance of integrated curricula

\section{Legal level}

- Establishment of legislation for recognition of awarding integrated degrees.

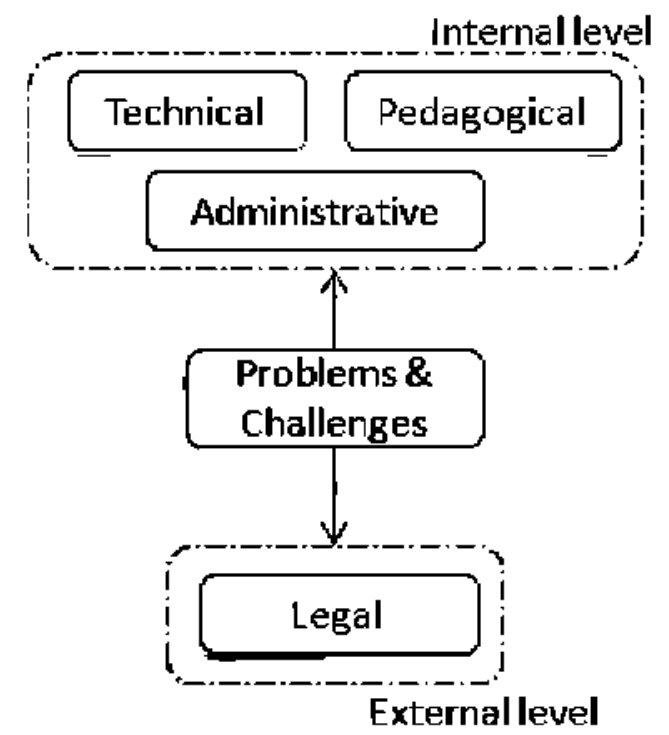

FIGURE 2

PRCBLEMS \& CHALLENGES TO OVERCCME.

Our research and proposal focus on the technical issues (Figure 2). A service-oriented architecture is proposed to solve the technical problems generated by the heterogeneity of e-Learning systems. A new category of services is proposed due to the lack of services oriented toward the management of joint curricula.

In this context. a joint degree can be defined as an academic program, made up of a cluster of services that are offered by universities through their e-Learning systems [13]. These services will offer support to academic and administrative processes involved in an academic program. The services will be combined and federated. according to the agreement established by the universities involved.

Academic coordinators, managers, course designers, eLearning administrators, teachers and learners are the roles identified to participate in this scenario.

The development of a proof-of-concept prototype was the method used to evaluate the performance of the $E$ leaning systems in a collaborative environment. To achieve this goal, we have used an open source platform, such as Moodle and a proprietary platform like Blackboard.

\section{Proposed ARChITECTURE}

The results of our research into e-Leaming frameworks, have allowed us to identify and specify a new category of services called "Joint Degree Services", which define the missing services in other e-leaming frameworks to allow the development of joint degrees in e-Learning systems.

This category is made up of the following services, which should be implemented by each e-Learning system to support the development of integrated study programs:

- Management of courses: information. publishing and execution of services

- Management of administrative process

- Management of access control

- Management of privacy and security

- Notification of Services: reporting any events in the services

- Management of collaboration agreement: specification through templates. electronic signature and translate into a policy language

- Design of joint curricula

Management of assessment in a collaborative environment

By considering the advantages of the service-oriented frameworks, we propose the design of a federated serviceoriented architecture made up of a policy editor, a policy manager. a workflow engine, a service manager. an identity provider, an UDDI extension and service providers (eLearning systems). The implementation of our approach will be based on Web Services.

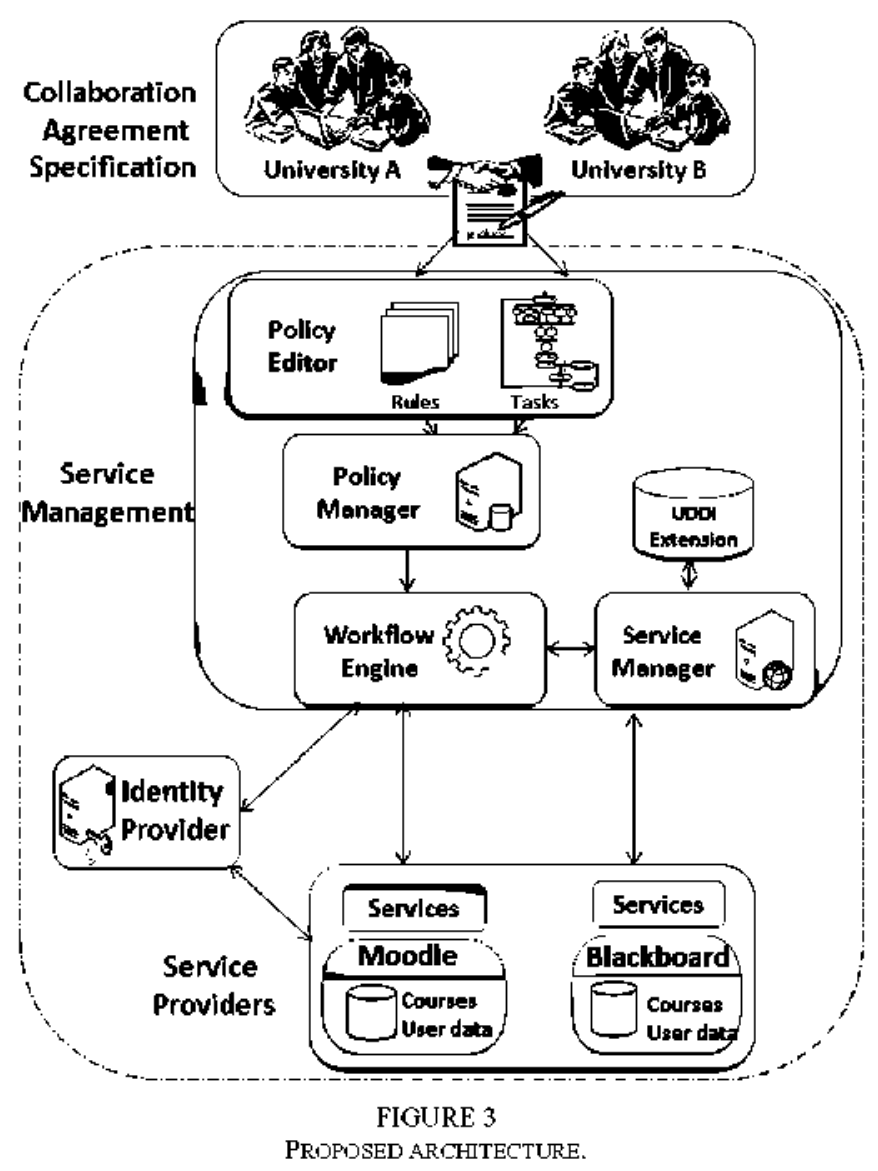


This architecture will be federated by policies in accordance with the collaboration agreement signed by the participating universities. The overall architecture is illustrated in the Figure 3.

The collaboration agreement specification is a manual process which depends on the signing of the legal representatives of each institution. It would specify the following aspects:

- Purpose

- Joint curricula

- Language of instruction

- Teaching and administrative staff

- Administrative matters: registration, enrolment, evaluation, tuition costs

- Access control and security policies.

- Duration and conditions of the agreement.

- Admission requirements for students

- Enrolment rules

- Credit format

- Responsibilities and tasks

- Legal aspects

Once the agreement has been signed, it will be specified in terms of rules and tasks thought a policy editor. Each task fulfils a functional requirement. The policy editor enables the e-Learning administrator to define policies expressed as sets of rules, which can be translated into policy language like BPEL. In the same way, the policy editor allows administrators to define process expressed as tasks. These policies and process will be sent to the policy manager.

The policy manager is responsible for editing, storing, activating, deactivating and deleting existing policies. Each policy is identified by an id and can be enabled or disabled. Policies allow administrators to modify system behavior without changing source code. Once the policies have been managed, the process and policies are sent to the workflow engine.

The workflow engine is responsible for managing the federation and orchestration the process according to the policies. Each process is identified as a service. The workflow engine will enable and execute services in accordance with the information specified in the collaboration agreement (nules and process). The service information will be provided by the service manager.

The service manager is responsible for identifying services that can be required in this scenario. The identified services are submitted to the policy manager, which will bind the services according to the policies specified in the agreement. In order to support the service federation, all educational services need to be registered in a central repository.

We propose to use an UDDI extension as a central directory for services registration and services discovery. The service information described by Web Service Description Language (WSDL) is registered in the UDDI extension directory. The services are discovered and invoked in accordance with the user requests.
Service providers or universities are responsible for publishing and offering services that allow access to other eLearning services. The published services will access the content shared by the university. Each service provider will publish policies for the use of their services and define how these services can be invoked. Each shared resource must have a service assigned to it and published in the UDDI extension directory.

The identity provider is responsible for controlling the identity and validity of users. It supports role-based access control. The user registration service will store the user information (e.g. username, password. registry course, etc) in the user profile.

According to the service implementation complexity in the e-Learning systems, we can make up of eight levels of integration (Table I).

TABLE I

IMPLEMENTATION LEVELS

\begin{tabular}{cl}
\hline Level & \multicolumn{1}{c}{ Services } \\
\hline 1 & Managenent of courses \\
2 & Management of access control \\
3 & Notification of Services \\
4 & Design of joint curricula \\
5 & Managenent of privacy and security \\
6 & Management of assessment in a collaborative environment \\
7 & Managenent of administrative process \\
8 & Management of collaboration agreement \\
\hline
\end{tabular}

We have developed a prototype to validate our approach using Moodle and Blackboard. They offer support to extensions and web services that allow us to create the proposed services in the levels 1,2 and 3 .

\section{CONCLUSIONS AND FUTURE WORK}

A service-oriented architecture is proposed to solve the technical problems generated by the development of integrated study programs through e-Learning. Pedagogical challenges can be solved applying a suitable approach [14]. In the same way, administrative problems can find solution implementing new business models. From our point of view. legal obstacles are the main barriers to this scenario becoming a reality

At the technical level. a new category of services called "Joint Degree Services" is proposed. This category should be implemented by each e-Learning system to support the development of integrated study programs.

Service-oriented architecture provides a correct framework to control and develop integrated study programs through e-Learning systems. It will allow the development of new joint curricula and the participation in the convergence of Higher Education. Furthermore, they offer academic institutions opportunities to consolidate partnerships, augment and diversify their academic programs, promote the accessibility of content and services, foster the internationalization and gain prestige and reputation.

We have developed and tested a prototype based on web services using Moodle and Blackboard. They offer support 
to extensions and web services that allow us to create the proposed services in the levels 1,2 and 3 .

Currently, we are working on the implementation of the rest proposed levels, which include the management of: joint curricula, privacy and security, assessment, administrative process and collaboration agreement. Likewise, we are designing and implementing a policy editor to automatically translate a collaboration agreement into a policy language like BPEL.

The use of e-Learning as a tool to support integrated degrees will avoid plysical mobility for both students and teachers and problems such us: costs of travel and accommodation visa application process. social security. etc. In this context, universities will save time. money and space limitations on mobility.

In order to facilitate the interoperability among eLearning systems, it is important to promote the use of standards to specify: academic calendars and learning objects.

Moreover, the specification of standard for comparing and transferring degree credits and grades credit systems is needed. In Europe, the European Credit Transfer System (ECTS) is the standard European system according to the Bologna process.

Our future work will focus on the implementation of our approach in a real scenario using the Moodle of our department and the blackboard used by the SENA in Colombia.

Furthermore, tests using different systems of e-Learning from our university will be carried out.

\section{REFERENCES}

[1]. Wilson S, Blinco K, Rehak D, "Service-oriented frameworks: modelling the infrastructure for the next generation of e-Learning Systens". Joint Information Systems Committee (IISC), 2004.

[2]. Moodle, http://moodle.org/, accessed on March 10, 2010.

[3]. Blackboard, http://www blackboard.coni, accessed on February 12, 2010 .

[4]. Kuder M, Obst D, "Joint and double degree prograns in the transatlantic context: a survey report", Institute of International Education and Freie Unversität. Berlin, 2009.

[5]. Knight, J, "Joint and double degree programmes: vexing questions and issues", The Obsenatory on borderless higher education. London, 2008.

[6]. The Berlin Communique, "Realising the European Higher Education Area", Communique of the conference of ministers responsible for higher education, Berlin, Germany, September, 2003.

[7] Sinon B, Massart D, Vau Assche F, Teruier E, et al."A simple query interface for interoperable learning repositories", Proceedings of the Ist International worhshop on interoperabihty of web-based educational systems. Cliba, Japan, 2005, pp. 11-18.

[8] Aguirre S, Brantner S, Huber G. Markus S, et al, "Corner stones of semantic interoperability demonstrated in a smart space for learning", Poster Proceedings of the European Semantic Web Conference. Greece, 2005.
[9] CORDRA (Content Object Repository Discovery and Registration/Resolution Architecture), http://cordra.net, accessed on February 15, 2010.

[10] The E-Learning Framework, http:/www,elframework.org, accessed on February 15, 2010.

[11] Open Knowledge Initiative, http:/iwww,okiproject.org, accessed on February 15,2010 .

[12] Tauch C, Rauhvargers A, "Survey on master degrees and joint degrees in Europe", European Unversity Association. Brussels, 2002.

[13] Aguitre S, Quemada J. Salvachúa J, "Wotk in progress-developing joint degrees through e-Learning Systems", Frontiers in Education Conference, Saratoga. USA, 2008.

[14] Ask, B. \& Haugen, H. "Pedagogical approaches to e-Learning". Proceedings of the World conference on edicational multimedia, hypermedia and telecommumcation. Lugano, Switzerland ,2004, pp. 3515-3520.

\section{AUTHOR INFORMATION}

Sandra Aguirre, PhD Student, Department of Telematic Engineering, Universidad Politécnica de Madrid, saguirre $(\bar{a})$ dit upm.es

Juan Quemada, Professor, Department of Telematic Engineering, Universidad Politécnica de Madrid, jquemada $(\underline{a})$ dit upm.es

Joaquín Salvachúa, Associate Professor, Department of Telematic Engineering, Universidad Politécnica de Madrid, jsr $(\underline{\text { dit upm.es }}$ 